\title{
Biopsy and Surgical specimen anatomopathological concordance of aspiration, curettage and hysteroscopy in endometrial cancer patients
}

\author{
C. Anton, E.V.L. Mayerhoff, R.T. Kleine, J.P. Carvalho \\ ICESP - Instituto do Câncer do Estado de São Paulo
}

\section{Objectives}

To explore the anatomopathological concordance of different diagnosis methods in endometrial cancer.

\section{Methods}

A retrospective analysis of 824 patients with endometrial cancer diagnosis referred to surgical treatment in Instituto do Câncer do Estado de São Paulo between January 2009 and February 2019 was performed. Data has been exported from the REDCap database.

The proportions of concordance of the exact anatomopathological results (histological type and grade) and the histological grade alone (high or low grade) between the diagnostic biopsy and the surgical specimen were calculated and compared for the following methods: endometrial aspiration, curettage and hysteroscopy (diagnose and operative).

\section{Results}

From the 824 analyzed patients, 628 had histological results from both a diagnostic biopsy and the surgical specimen. The diagnosis methods analyzed were: endometrial aspiration, curettage and hysteroscopy. The proportion of anatomopathological concordance between biopsy and surgical specimen can be seen in table 1. The exact concordance taking into account the histological type and grade was analyzed and in a second analysis the histological grade alone was evaluated. Table 2 shows the comparison of the different methods.

\section{Conclusion}

Endometrial cancer diagnosis through endometrial aspiration or curettage had a better correlation of the histological grade with the surgical specimen when compared to hysteroscopy. In addition, endometrial aspiration is a cheaper and more accessible method than hysteroscopy and should therefore be stimulated as a diagnostic method for endometrial cancer.

Table 1: Hystological concordance between biopsy and final specimen in different diagnosis methods

\begin{tabular}{|c|c|c|}
\hline & Exact concordance & Grade Concordance \\
\hline Endometrial aspiration & $53.8 \%$ & $73.1 \%$ \\
\hline Curettage & $51.5 \%$ & $71.3 \%$ \\
\hline Hysteroscopy & $51.1 \%$ & $64.1 \%$ \\
\hline
\end{tabular}

Table 2: Proportion concordance diagnose comparison between different diagnosis methods

\begin{tabular}{|c|c|c|c|c|}
\hline & Exact concordance & $p$ & Grade Concordance & $p$ \\
\hline $\begin{array}{c}\text { Aspiration } \mathrm{x} \\
\text { Hysterocopy }\end{array}$ & $53.7 \%(0.436-0.639) \times 51.7 \%(0.459-0.562)$ & $p=0.32$ & $73.1 \%(0.641-0.821) \times 64.1 \%(0.592-0.69)$ & $p=0.05$ \\
\hline $\begin{array}{c}\text { Curettage } \mathrm{x} \\
\text { Hysteroscopy }\end{array}$ & $51.5 \%(0.439-0.591) \times 51.1 \%(0.459-0.562)$ & $p=0.47$ & $71.3 \%(0.644-0.781) \times 64.1 \%(0.592-0.69)$ & $p=0.05$ \\
\hline $\begin{array}{c}\text { Aspiration } \mathrm{x} \\
\text { Curettage }\end{array}$ & $53.8 \%(0.436-0.639) \times 51.5 \%(0.439-0.591)$ & $p=0.36$ & $71.3 \%(0.643-0.781) \times 72.1 \%(0.626-0.816)$ & $p=0.55$ \\
\hline
\end{tabular}

